\title{
Knowledge power nexus in Nepal's community forest planning
}

\author{
Srijana Baral $^{* 1}$ and Prabal Bir Jung Rana ${ }^{2}$ \\ 1 Forest Action Nepal, Lalitpur, Nepal \\ 2 Nanjing Forestry University, China
}

\section{KEYWORDS}

Scientific forestry

Bureaucracy

Community forest users

Remote sensing

\begin{abstract}
The forest management plans started as simple document turned to complex silviculture based plans that included compartmentalization and detailed mapping of the forests. Several researches focused on the community forestry outcomes, but there is a paucity of studies on the implications GIS based mapping of small patches of community forests from the users perspectives. The plans have switched the users from adopting local knowledge to technical scientific knowledge. Thus, this paper explores the understanding of local communities about the forests and implications of complex GIS tools in community forestry. Taking a case study approach, this study compared participatory maps produced by the local communities with the maps produced through Landsat Image classification in terms of accuracy, acceptability by the local users and associated costs. Semi-structured interviews of community forest user groups and forest bureaucracy and focus group discussions with the users were carried out to analyse the significance of the role of GIS based mapping in community forest management. The findings revealed that participatory maps performed better in terms of accuracy, cost and acceptability by the users. The local communities found it difficult to interpret the GIS-based maps. The users considered that the forest bureaucracy is using these GIS-based maps as a means of controlling the users from a distance. Hence, blending of local and scientific knowledge will yield better results and increase the ownership of technical interventions in community forestry.
\end{abstract}

\section{Introduction}

In Mid-hills of Nepal, community forests are generally, small patches of forest handed over to the local forest user groups to develop, conserve, use and manage such forest, and sell and distribute the forest products by independently fixing their prices as conditioned in their Community Forest Operational Plans (CFOP) (GoN 2019). However, this autonomy of the user groups is hindered by different management planning approaches devised by the government. Technical sophistication of forest management planning is increasing 
from simple management plans to scientific forest management plans (SciFMPs). With the introduction of scientific forest management planning in community forests, the Operational Plan preparations were hugely burdened by technical jargons and actions (Baral et al. 2018). For almost a decade, the scientific forest management though the preparation of SciFMPs became a high priority program of the Government of Nepal (GoN/MoFE 2019). However, the meeting of the Council of Ministers on January 24, 2021 decided to dismiss the program and the Scientific Forest Management Guidelines and Procedures. Several issues with the governance aspects in SciFM were reported (Poudyal et al. 2020; Basnyat et al. 2018).

In the Nepalese context, scientific forestry principles and technical interventions have rendered the forest bureaucracy more powerful at the cost of local people's participation (Baral et al. 2018; Lund 2015; Rutt et al. 2015). The scientific framing had enabled the forest bureaucracy to adopt the form of knowledge requiring expertise and hence elevate them to superior positions (Nightingale 2005). These forms of knowledge often disregarded the local realities and demanding new technical capacities where, the communities had to become overly-reliant on the forest bureaucracy for financial and technical support. Use of colonial era scientific knowledge in forestry has been limiting the use of local knowledge in management decisions. The legacy of colonial forestry science is well reflected in technical prescriptions and territorialisation requirements including GIS-based maps.

Scientific representations of forest change using remote sensing techniques are becoming increasingly dominant for assessing environmental problems in forestry sector because they are perceived to be more reproducible and generalizable with limited field data (Ahlborg and Nightingale 2010). However these forms of technology development have implications on the quality of information, credibility and legitimacy of different knowledge systems resulting in mismatches between the scientific scales of observation and scales of knowledge (Ahlborg and Nightingale 2012).

A map is both a real, physical thing that exists in a certain place and time, but it is also considered as a political feat and economic activity regarded as a matter of power and inequality reproducing unequal social relations (Hodgson and Schroeder 2002). Mapping of the forest or any other land-use has become power control tool for the States since the 18th Century (Scott 1998). Mapping is regarded as "a science of the princes"; the statement itself implies the need of expertize and consequent costs that opens spaces for power struggles around the control and knowledge of mapping technologies (Peluso 1995). Maps have long been used to legitimize the reality of conquest and is a literal and figurative colonization of space (Mignolo 1992). Thus, mapping of forest resources is, therefore, an intrinsically political act: whether drawn for their protection or production, they are considered as the drawings of a nation's strategic spaces (Peluso 1995). They are linked to power dynamics such as colonial conquest for planning, monitoring and informing public policy discussions (Klopp and Sang 2011). Such practices have emerged and are increasingly being used in community forestry in Nepal.

Thus, this paper explores how the application of scientific knowledge makes one actor (actor possessing technical knowledge) powerful over other (at the expense of others). By seeking the differences in knowledge regime, we explain our case using political ecology theme of 'local' versus 'scientific' knowledge. We explore if the forest management appears useful to the local communities i.e., is the management taking place on an 'informed' basis. We concentrate our study of community forests in the Western hills of Nepal. As the community forestry in Nepal is in transition to increasing technicality, we seek to understand how mapping exercises in community forestry are taking place as 
political acts. Thus, we examine the usefulness of the mapping exercises conducted in community forest management, as well as how they are related to forest governance issues; secondly we discuss how the colonial discourses survive in contemporary forestry through mapping exercises. To do so, we first compare the map produced using Landsat image with the participatory map produced with support from the local communities. We then explore the usefulness of mapping exercise in community forestry from the community forest user's perspective and then analyse the role of such maps in the context of decentralized community forestry.

\section{Case study area}

The study was conducted in a Mid-hill district in the Western region of Nepal. Mid-hill that was selected as community forestry is regarded as a successful participatory forest management regime in Nepal (Pokharel et al. 2012). The selected district had been implementing community forestry for more than 20 years and was among the ones initiating participatory forestry programs in Nepal. A cluster of nine CFUGs within one administrative boundary (Village Development Committee-VDC) ${ }^{1}$ was selected. At the time of VDC selection, VDC that comprised CFUGs practicing different forest management modalities (i.e. CFOPs and SciFMPs) were selected. Out of nine CFUGs, five of them were implementing classical (management plans based on 2004 inventory guidelines and its renewals) regarded as ordinary CFOPs and others with 'Scientific Forest Management Plans ${ }^{2}$ (plans prepared based on the Scientific Forest Management Guidelines) where, the technical Forestry: Journal of Institute of Forestry, Nepals are prominent (See Baral et al. 2018). The study area covers an approximate forest area of 500 ha and benefiting more than 600 households (Table 1). The name of the district and the names of the community forests are not disclosed, to ensure anonymity of respondents.

\section{Materials and Methods}

Several methods of mapping and questionnaire survey were carried out. The field work took place between June-2016 to December-2016. A follow up visit to the CFUGs was carried out every year since then i.e. 2017, 2018 and 2019.

\section{Participatory mapping}

Mapping is one of the important tools for land use and land cover decisions. We adopted different approaches of mapping exercise i.e. analysis of land cover using remote sensing image analysis and participatory mapping to observe the knowledge of the local community about the land-cover in their vicinity. Participatory maps have become a popular means of information

Table 1: Basic characteristics of case Community forests

\begin{tabular}{ccccl}
\hline $\begin{array}{c}\text { CFUG } \\
\text { Code }\end{array}$ & $\begin{array}{c}\text { Area } \\
\text { (hectare) }\end{array}$ & $\begin{array}{c}\text { Households } \\
\text { (Number) }\end{array}$ & $\begin{array}{c}\text { Year of } \\
\text { handover }\end{array}$ & \multicolumn{1}{c}{ Major Tree species } \\
\hline 1 & 40.34 & 104 & 1998 & Shorea robusta, Schima wallichii, Castanopsis indica \\
2 & 14.54 & 60 & 2012 & Shorea robusta, Schima wallichii \\
3 & 13.36 & 31 & 2000 & Shorea robusta, Schima wallichii \\
4 & 85.10 & 86 & 1999 & Shorea robusta, Schima wallichi, Castanopsis indica \\
5 & 12.04 & 50 & 1995 & Shorea robusta, Schima wallichii \\
6 & 64.92 & 54 & 1996 & Shorea robusta, Schima wallichi, Castanopsis indica \\
7 & 94.22 & 61 & 1996 & Shorea robusta, Schima wallichi, Castanopsis indica \\
8 & 89.49 & 116 & 1996 & Shorea robusta, Schima wallichi, Castanopsis indica \\
9 & 84.74 & 58 & 1996 & Shorea robusta, Schima wallichi, Castanopsis indica \\
\hline
\end{tabular}

1 A Village Development Committee (VDC) was a lower administrative part of the government. VDC was dissolved on 10th March 2017 to be replaced by "Palika-Municipality" after the federal.

2 Scientific forest management is currently dismissed. 
collection in natural resource management to gain a deeper understanding of local people's perceptions of their environment (Carter 1996; Chambers 1994).

Participatory mapping was done in June/July, 2016. For conducting participatory mapping, a group exercise was carried out in each community forests. Each group consisted of 6-8 members from the respective CFUGs and more than $50 \%$ of them were people above 50 years. This was done to trace the historical evidences on changes in land-cover, more importantly forest-cover in the area, in addition these people are in CFUG executives for long time and more importantly there is lack of young people in the village. Two approaches of mapping were taken, firstly the users were allowed to draw the map of their village in a plane sheet and later they were asked to do the same in the base map provided to them. The base map (see- map 1a) included the village boundary, major road networks, river and seven permanent features. The participants first drew the boundary (ward in the village represented the CF and CFUGs), then added the permanent features and categorized the land into seven categories i.e. agriculture, Shorea robusta forest (two classes, dense and sparse), Schima Castanopsis forest, barren or sand, settlement and water bodies as described in Table 2.

The users first drew the features with pencil and after the map was finalized, the features were over-written using a marker by a research assistant, after the local people finalised the map. The over-writing was done in presence of the local people involved in participatory mapping. The maps thus prepared were validated by another independent group consisting of 3 members from each CFUG.

\section{Digitization of participatory maps}

These participatory maps were then scanned to highest resolution, and were digitized using ArcGIS 10.3 creating a shape-file. They were validated using ground collected points for all classes except water, and for water, the test points were collected from Geo-Eye image ${ }^{3}$.

\section{Classification of Landsat images}

The Landsat image for November, 2016 was downloaded from https://earthexplorer.usgs. gov/. Landsat is a 7-band multi-spectral image with $30 \mathrm{~m}$ spatial resolution. These images were then classified using maximum likelihood classification in ERDAS IMAGINE. The image could be classified into five classes only.

\section{Validation}

The image classification and participatory maps were validated with ground truth points (same points were used for participatory maps and remote sensing image analysis). Overall classification accuracy was assessed using Confusion Matrix and Kappa Coefficient. Confusion matrix compares the classification results with the ground truth information and provides the overall accuracy of the classification along with quantification of errors in them. Overall accuracy (the percentage of

Table 2: Description of land-cover classes

\begin{tabular}{cll}
\hline S. $\mathbf{N}$ & Land cover classes & \multicolumn{1}{c}{ Description } \\
\hline 1 & Agriculture & Agriculture areas both currently cultivated and fallow land \\
2 & Dense shorea & Land areas covered with Shorea trees with more than 40\% canopy cover \\
3 & Sparse shorea & Land areas covered with Shorea tree with less than 40\% canopy cover \\
4 & Schima Castanopsis & Land areas covered with Schima castonopsis forest \\
5 & Settlement & Major settlement areas consisting of buildings \\
6 & Barren/Sand & Areas with no vegetation cover, stony areas, uncultivated agriculture land and \\
7 & Water bodies & Randy river banks \\
\hline
\end{tabular}


points that were classified correctly) estimates the overall reliability of the classification. Producer and user accuracy were calculated for the individual map classes. Producer's accuracy (error of commission) is the probability that a point on a map is correctly categorized by the classification scheme; while the user's accuracy (error of omission) estimates the probability that the class assigned to a point on the map accurately represents what is on the ground. Kappa Coefficient is a measure of observational probability of agreement with a hypothetical expected probability of agreement under an appropriate set of baseline constraints (Landis and Koch 1977).

\section{Cost of mapping}

To examine the cost of preparing maps, calculation of the cost for different mapping exercises, actual cost incurred during the process was used. The cost calculation included reconnaissance survey, field survey, validation survey or field data collection, data entry, data processing and map creation, cost of images and software. The reconnaissance survey involved visiting the place and being acquainted with the community forests and the user groups; it took only two days for participatory mapping. It was important for us to build trust with the local communities before we could start our exercise, however for remote sensing image analysis, reconnaissance survey was not necessary (minimum of it was done during training samples collection). Field survey was carried out only in case of participatory mapping, where the small groups of people (6-8) were gathered to prepare and three people from each group were used to verify the maps in case of participatory maps. Data collected from either source had to be validated; for that purpose, GPS points were collected, which were later categorized to training and test samples to train and assess the accuracy of the maps prepared. Hence, validation was required for both the techniques, but the cost of resource persons having image analysis techniques was higher as it was required expertise in image analysis. Same input was required to enter the data collected in the field, but the number of days spent in data analysis was different in both the cases. In participatory mapping, the maps were scanned and digitized while the process was lengthy in case of remote sensing image.

For examining the reasons for changes in the forest condition and exploring perceptions of the users on the use of GIS based maps, household $(\mathrm{HH})$ survey and Focus Group Discussions (FGDs) (nine) were carried out. HH Survey including $20 \%$ of the total $620 \mathrm{HHs}(\mathrm{n}=125)$ was done from January to March 2016. The interview questions focused on the acceptance of the GIS based maps, changes in the forest cover and management planning. Similarly, focus group discussions carried out to verify the changes in the cover and people's perceptions on the changes. The major focus of the discussion was on the history of forest management, change in forest cover in relation to other land-cover classes in the village and assessing the reasons for such change.

Both the qualitative and quantitative methods of data analysis were conducted. The household survey data were entered into Microsoft Excel spread sheet and they were coded for obtaining comparable results. The notes of focus group discussions were used to build narratives. The field-books were maintained during the formal and informal discussions which were later used to build narratives in light of the interviewee, and information about the topic of the interview gathered during the field study.

\section{Results}

Comparison of participatory map with the map prepared through remotely sensed image analysis

3 Geo-Eye is a very high-resolution image which was fused to $50 \mathrm{~cm}$ spatial resolution with 4 spectral bands. 

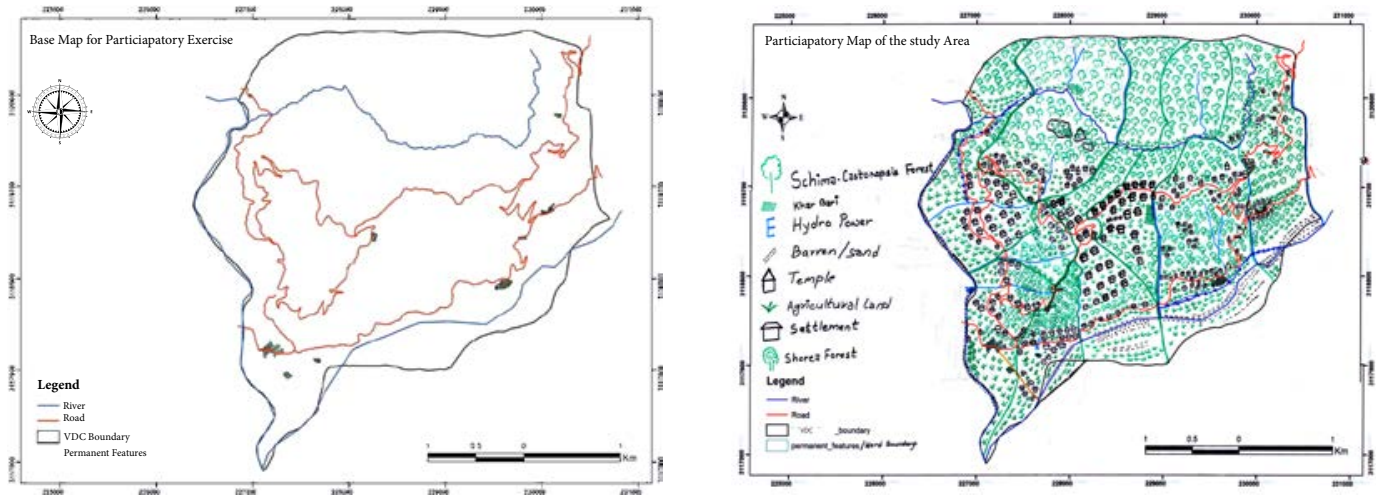

Map 1a: Base map of the study area provided for participatory mapping 1b: Participatory map of year 2016

\section{Accuracy assessment}

The remote sensing image classification, using Landsat image appeared to be poorly performing in comparison with the participatory map. The number of classes that could be identified in $30 \mathrm{~m}$ resolution Landsat image was obviously less than the participatory maps. Landsat image could only classify the land cover into five classes while in case of participatory map; the participants could classify the land cover into six classes (See map 2a and 2b).

Participatory mapping exercises were successful at identifying different

Land_cover class Agriculture

\section{Barren/sand}

Schima Castonopsis forest

Shorea forest

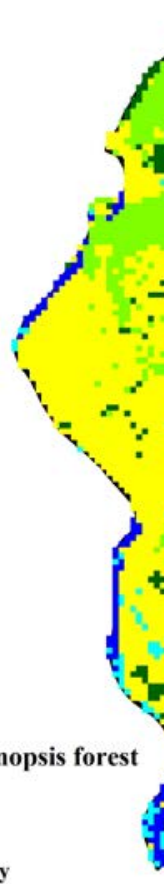

Water

Village boundary 


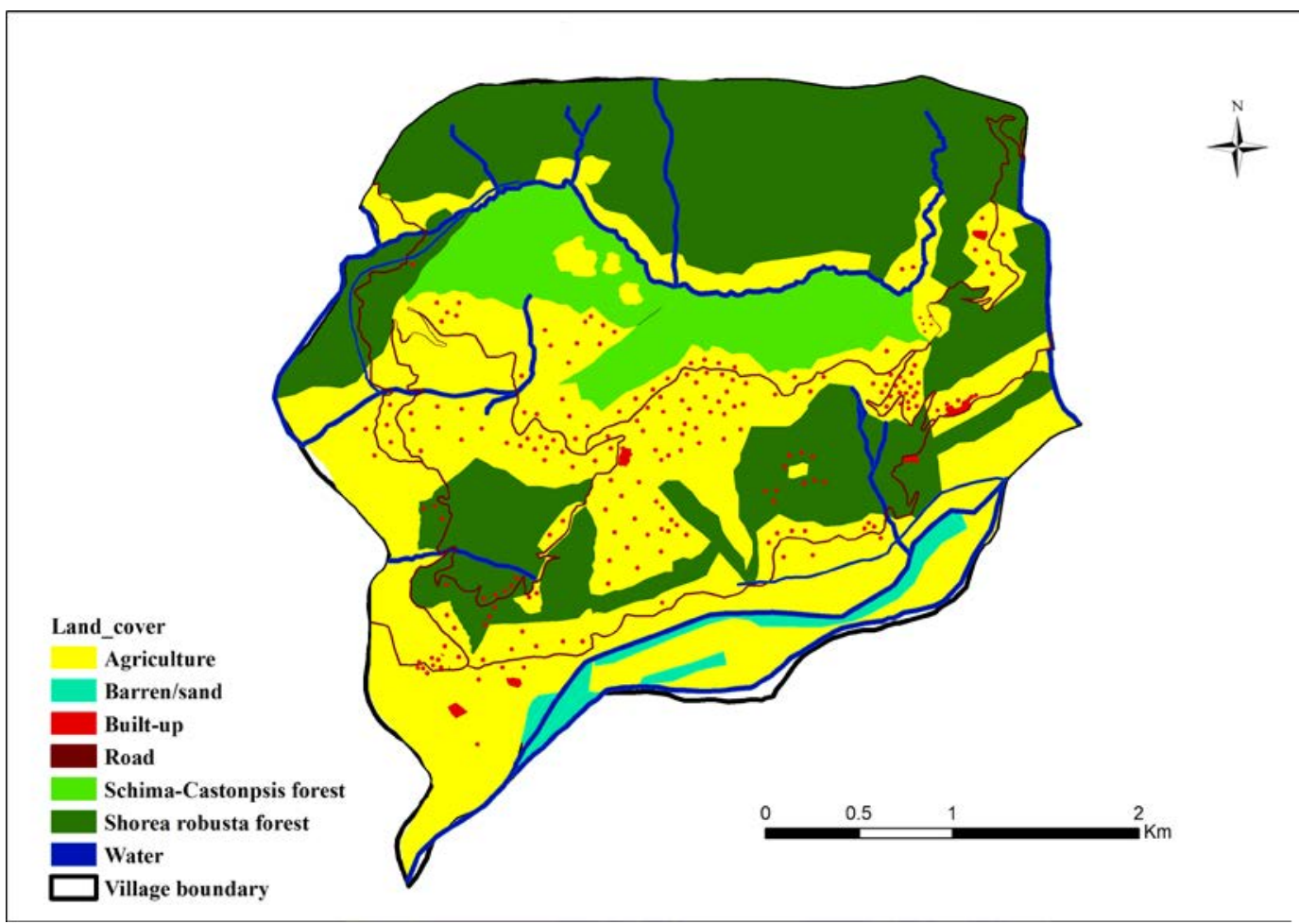

Map 2 b: Land-cover map of Year 2016 derived from Participatory map

forest species, forest compartments and interventions carried out in different years. The participants could spatially identify the individual households and land parcels as well which was difficult with Landsat image. Apart from number of classes, the accuracy assessment of the images showed that the participatory map was more accurate compared to Landsat image. Since having the class 'roads' in classification significantly reduced the accuracy of classification in Landsat, it was dropped while the roads were very interestingly evaluated during the time period in participatory mapping.

The accuracy assessment of the participatory maps demonstrated higher overall classification accuracy of $86.33 \%$ and the overall kappa statistics is 0.83 (Table 3) compared to the overall classification accuracy of $83.33 \%$ with overall kappa statistics of 0.77 . Thus, the participatory map could recognize more features with greater accuracy compared with the analysis of Landsat image.

\section{Cost and time taken}

When we analysed the cost of preparing and using participatory maps and maps produced from remote sensing image analysis, we found that the cost of participatory mapping was low. Since the image was freely downloaded from Earth explorer, the cost of purchasing the image was not taken into account in this study; however, the purchase of software would incur additional costs. The findings reveal that the cost of Landsat image analysis was more compared to participatory mapping i.e. USD 950 versus USD 2500 especially in the context of small patches of community forestry (Table 4). Even if the cost of software is into consideration, the overall cost mapping is less in participatory mapping exercise. 
Table 3: Accuracy assessment of land-cover classification based on participatory mapping and image analysis

\begin{tabular}{lccc}
\hline & No of classes & \multicolumn{2}{c}{ Accuracy assessment } \\
& 7 & Overall classification & accuracy (\%) \\
Oarticipatory mapping & 5 & 86.33 & 0.83 \\
Image Analysis & 5 & 83.33 & 0.77 \\
\hline
\end{tabular}

In addition, the participatory mappings were found to be very interactive and CFUGs enjoyed the exercises while the Landsat image had to be downloaded, processed and analysed using ERDAS IMAGINE software. Hence the time required for participatory mapping was half the time required for remote sensing image analysis.

Hence, maps prepared using Landsat image were more expensive and requires greater technical expertise and capacity to understand and analyse. If the image of higher resolution were to be used, the expenses would definitely increase at cost of better accuracy.

\section{Ownership}

Local communities were found to be keen on drawing their forest by themselves through participatory mapping process compared to the map produced through using GIS/Remote sensing technique. Since, the users involved in participatory mapping were middle/old age people (most of them above 50 years of age) they find forest management as their responsibility, and the satellite images cannot identify the tenure of the land property "I think we know it best, let me tell you a funny thing, the consultant came to us and took measurements of the trees and also the boundary points, but later

Table 4: Comparison of cost incurred for participatory mapping and mapping using Landsat image analysis

\begin{tabular}{|c|c|c|c|c|c|c|c|}
\hline \multirow[b]{2}{*}{ Task } & \multicolumn{3}{|c|}{ Participatory mapping } & \multicolumn{3}{|c|}{ Remote sensing } & \multirow[b]{2}{*}{ Remarks } \\
\hline & $\begin{array}{c}\text { Cost } \\
\text { per day } \\
\text { (USD) }\end{array}$ & $\begin{array}{l}\text { No of } \\
\text { days }\end{array}$ & $\begin{array}{l}\text { Total cost } \\
\text { (USD) }\end{array}$ & $\begin{array}{c}\text { Cost } \\
\text { per day } \\
\text { (USD) }\end{array}$ & $\begin{array}{l}\text { No of } \\
\text { days }\end{array}$ & $\begin{array}{l}\text { Total cost } \\
\text { (USD) }\end{array}$ & \\
\hline $\begin{array}{l}\text { Identifying field sites } \\
\text { (Reconnaissance survey) }\end{array}$ & $100^{4}$ & 1 & 100 & 100 & 1 & 100 & $\begin{array}{l}\text { 2-member } \\
\text { crew (RA and } \\
\text { Researcher) }\end{array}$ \\
\hline $\begin{array}{l}\text { Participatory mapping } \\
\text { exercise }\end{array}$ & 100 & 4 & 400 & 100 & 0 & 0 & \\
\hline $\begin{array}{l}\text { Field data collection } \\
\text { for training and test } \\
\text { (Validation) }\end{array}$ & 100 & 2 & 200 & 100 & 3 & 300 & \\
\hline Data entry & & & 50 & 100 & 1 & 100 & \\
\hline $\begin{array}{l}\text { Data processing and map } \\
\text { creation (Digitization } \\
\text { of PMs and RS image } \\
\text { download, processing and } \\
\text { analysis) }\end{array}$ & 100 & 2 & 200 & 100 & 5 & 500 & $\begin{array}{c}\text { Supervised } \\
\text { classification of } \\
\text { RS image }\end{array}$ \\
\hline Cost of purchase (images) & & 0 & 0 & & & 0 & Free image \\
\hline $\begin{array}{l}\text { Cost of purchase (software- } \\
\text { ArcGIS }\end{array}$ & & & 0 & & & 1500 & Single use \\
\hline Total (USD) & & 9 & 950 & & 10 & 2500 & \\
\hline
\end{tabular}

4 The cost per day includes the charge of the research crew 
when the map came, the map was so different from our community forest, the private land and house in the middle of the forest were omitted, we discussed about it with the technicians and they promised not to eliminate the private property within the forest area." The community forest user groups were also concerned about the maps present in their forest management plans. The usefulness of the map was not understood rather it was taken as a requisite content of the plan. Hence, the users accepted the maps without questioning its rationale.

Moreover, during boundary survey, one of the CFUG had boundary conflict with the neighboring VDC's community forest. The forest technicians could not solve the problem, however after several informal talks between the executives, the CFUGs agreed on creating a "no-man's zone" between their forests. The CF Chairperson shared the incidence, "During boundary delineation, many problems were faced in identifying the real boundary of CFUGs. Both of the CFUGs had several informal meetings and we both agreed to keep no-man's zones in the boundary area of $10 \mathrm{~m}$ from both sides where nobody undertakes any interventions". The issue is greater than creating maps and territorializing the CFs to different users.

\section{Local perceptions and usefulness of GIS- based mapping in forest management planning.}

The use of GIS-based maps is perceived to be a technical matter by the local communities and find it difficult to understand and regard the process as more technocratic approach to forest management planning. People have perceived it better, if the results of image classification shows that the people's knowledge on the local context is much useful. However, the local CFUGs are forced to accept the use of GIS-based maps because they are introduced by forest bureaucracy as a part of requirement of the technical plan. Consequently, this has created fear/anxiety amongst the local forest users in making decisions about forest management. In some CFUGs, the executive committee members fear that too much use of technology might reduce the ownership feeling that the local communities have in community forestry. The users do not find use of such technologies usual and comfortable. One of the CF chairperson shared that "the DFO has himself devised ways to monitor the forest, why should we bother". This statement is somehow leading to shifting the ownership of community forests due to excessive use of technology. The forest bureaucracy is becoming powerful through use of technology and the users consider the act as controlling from distance

In addition, the users also doubt on the accuracy of the maps prepared through remote sensing and GIS technology. One of the CFUG members shared his dissatisfaction as the local users were limitedly used in the mapping and validation of the maps produced in community forests. The user's understand that not everything in the forest can be seen from above, one of the CF executives shared that, "the experts say that they are using the photos taken from above (images), but we do not agree that everything can be seen from above, for example you cannot see the under-growths and climbers that are intermingled with the trees from above". Hence, they understand the maps used do not tell the complete story of the forest rather it is creating illusions.

In addition, the use of GIS-based maps in CFUGs is creating fear among the users. The CFUGs fear losing the power of managing forests due to excessive use of technology in forests that is already handed over to the users. One of CFUG chairperson shared that, "DFO sab once said he can monitor my forest from his computer in the office and we felt guilty, it's our forest, we have been conserving it for decades and now why is he treating as if we are thieves?" The changes in the forest management planning and the plan are becoming technically complex object after each renewal. One of the CFUG executives shared that "if we look back to our first plan, it had no forestry science in it. It was so simple and 
was focused on the daily operation of the CFUG and better conservation of the forest, then the plan had numbers after introducing inventory in forest management plans are technical, but still we were allowed to harvest timber based on the number but now, the plan has numbers and maps. It's gradually becoming complicated for us to understand and implement. The government is now seizing our rights from community forestry." During focus group discussions, all the nine CFUGs complained about the increasing rules and regulations constraining the autonomy that they were enjoying before. One of the Chairpersons, opined that "we feel like we are being bound by rules and regulations, we have no autonomy, we have no freedom of managing forest as we did before few years".

When the local communities were criticizing maps in the management plans while they were found to be owning the participatory maps produced. It is because they found many faults when the consultants mapped their area without involving them. The executive chairperson who had shifted to SciFMP in my visit to the study site in 2020 shared that the "tagging of the trees might be useful to the DFO but we see no significance of numbering the trees, we already know which tree is where." The tagging was found to be haphazard and difficult in identifying the trees in the forest. Not only during preparation, have the use of such maps created problems to the users but they have created issues in plan implementation too. The stem maps do not coincide with the trees tagged in the forest. This was more due to ignorance of the technicians involved in tagging the trees and mapping the trees in stem maps, "the tree number mentioned in the plan is not found in the field as the tagging is not done systematically and the tree in the map is not found in the forest, and we are restricted from harvesting even if the tree lies in the harvesting coupe". Since the tree numbers could not be found in the field, the users were denied the access to harvest the trees. When we inquired about it to the DFO, he said, "the tree tags are not found in the trees, the trees cannot be harvested, how can we know which tree is harvested and which one is retained, there will be issues during monitoring." In the recent visit to the CFUGs for collecting any new knowledge that has emerged at the local level, the individual tree tagging had become more problematic as the tags are now falling apart due to growth of tree trunks. This was commonly heard, the users said, "the tree continues to grow the tin tags fall off the trees, again creating problem in identification and harvesting."

It is illustrated best by one of the CFUGs which was supported by DFO to prepare scientific forest management plan. The users were surprised to see a village border different on the map compared to what they had been thinking as border, for the villagers, the route taken by the rivers is regarded as a border and have been undertaking activities accordingly, which did not match with the map in the plan. There are some issues with the process too, in some cases; the maps are produced without following appropriate procedure. One of the users explained to us that he can help us delineate the boundary by staying in a hill top (he took us to that place, because he could show the whole forest from that particular point), this shows that people are not serious about the survey. In another community forest, users explained that, "when the map was prepared, it looked so beautiful, but when we saw our house and private land inside the community forestry boundary, we had to reject the map".

\section{Discussions}

The findings of this study reveal that the local communities have a clear understanding of their forest and the other land cover as a whole. The participatory mapping exercise performed better in terms of accuracy, cost and the mapping process was also owned by the local communities. Moreover, the local communities find GIS based mapping to be more technocratic and as a mechanism devised by the forest bureaucracy for imposing the additional technical burdens 
in forest management planning. However, the forest bureaucrats acknowledged the significance of local knowledge but also believed that the expert knowledge they held was superior to the local communities for technically managing the forests. Thus, it raises the question against the use of scientific notion in management planning which highly disregards the local socio-economic, ecological and political dimensions of forest management in Nepal's community forestry.

The local CFUGs showed huge ignorance to the maps in the management plans but the map they prepared in a participatory manner revealed that the local people's knowledge on the trees inside the forest was good. They could identify and recognize almost all the features in the villages. Hence the mapping differs with the interest of the users and what is important to them. This finding corroborate with the findings of Robbins (2003) who found the land cover classification performed by foresters was different from that of local herder groups, the classification was found to be hugely driven by the interest of the people making the classification. The classification of the local herders was more convenient for them rather than the classification made by the foresters. Hence, mapping becomes a political act as it changes power relations between forest user groups and forest technicians (Robbins 2003). Similarly, Goldman (2003) describes how the exclusion of Maasai knowledge in conservation efforts underway in Northern Tanzania further marginalizes those populations, and discourages more flexible land-use management possibilities to which local knowledge may be particularly well-suited. The literature on power of maps, show that map forms have often been delegitimized or excluded in the face of Western techniques, despite the fact that such alternative mapping practices often convey highly intricate spatial relationships (Harris and Hazen 2005). The mapping approach in community forestry reflects colonial cartography that created a territory in which indigenous land use were made invisible (Sax 2020). Early colonial maps were a fundamental part of generating a body of knowledge that justified the hegemonic discourse of increasing power to the forest bureaucracy (Scott 1998).

In addition, the use of GIS-based maps in the participatory forestry is regarded as a mechanism of territorializing the forest land and increasing government's presence in community forestry. In fact, many researchers believe that maps are not an accurate representation of reality instead they are created by people for specific reasons and end up representing social disorder and relationships of powers (Peluso 2005). Hence, forest maps are considered an important tool for state authorities trying to exclude or include people within the same spaces as forest resources. Maps increase state control over spaces which are sources of social unrest and valuable resources (Peluso 1995).

The map prepared through remote sensing image performed poorly. The main reason being the resolution of the image, the poor resolution of Landsat image restricted the image to capture the details of the land-cover. Even, if the resolution did not matter, the natural components below the tree canopy would not be known with passive sensors (Robbins 2001). To be specific, in our case, the participatory map was able to identify the edges/border between the forest and private property, individual households and even the smallest streets and patches of agricultural field and trees which were not discernible in the Landsat image. This finding is similar to a study conducted by Ahlborg and Nightingale, (2012), where the management plans and maps are based on different and fewer temporal and spatial scale than the knowledge held by local users. The maps produced from remotely sensed image analysis represents a detached position, at a larger scale and without the detail of the local condition on the ground or in particular it detaches the community forest users from their interests (Ahlborg and Nightingale 2012). This is more evident as the use of remote sensing image analysis reduces the knowledge held 
by local actors and their relationship with the forest is ignored. High resolution images could solve the problem of increasing the accuracy of image classification, however, the cost and dilemma amongst the community members on the use of very sophisticated technology would further create fear. Hence, laudable integration of scientific knowledge with local knowledge is needed.

Furthermore, in a study by Turner and Hiernaux (2002), they have demonstrated that maps prepared through local people's participation proved to be effective and accurate for management than those rigorously developed through spatial modeling. Hence, for integration, there is a need for creation of circumstances where the mapping tool is employed to fit the needs, demands, and categories of planners and officials. For all of these reasons, the call for the incorporation of local, traditional, and indigenous knowledge in GIS is mounting, and a body of "indigenous GIS" is appearing in both the areas of analysis and management (Robbins 2003).

However, we do not dismiss the use of remote sensing techniques/GIS-based mapping for monitoring forest cover. If the technology becomes friendly and cheap, it can be a better means of forest monitoring which can collect data from the places that are inaccessible to people. If we take an example of mobile phone, it has become so handy and people are so much attached to it. So, the technologies should be friendly and accepted by the common people rather than being a tool to threaten them and their daily operation. Seeing local, traditional or indigenous knowledge as complementary to science is important which simultaneously lowers the risk of overlooking the differences within communities and between local knowledge systems (Ahlborg and Nightingale 2012) and hence, bridge the gap between local knowledge and experts knowledge.

In fact, local knowledge is precious and is based on long term observation and lived by the local communities. In case studies from Canada and
New Zealand, Moller et al. (2004) mentions that even though traditional and local knowledge related to natural resources may often be imprecise and qualitative, they are valuable because they are inexpensive and incorporate large sample sizes over a long period of time. It is generated informally through trial and error and in a participatory manner, while the scientific knowledge is usually formalized, mostly detached from the concrete case, and is generalised without adequate contextualization (Raymond et al. 2010). Our findings fit with these arguments as we find local people are knowledgeable about their community forestry and their knowledge is sufficient for daily management of community forests. This shows the strength of local knowledge in forest management. Moreover, scientific forestry is signature programme of the government of Nepal, the grassroot stakeholders perceive the scientific forest management skeptic and did not own the technical complexities in the management planning for possible bureaucratic dominance in community forestry (Poudyal et al. 2020).

However, central to these discussions are issues related to the relative value given to different forms of knowledge, with Western or technoscientific ideas often treated preferentially over traditional or indigenous ways of knowing, even as traditional knowledge systems may involve complex understandings of ecosystem processes, or as they may have successfully served to maintain ecosystems over long time periods (Reid et al. 2006).

Blending of scientific and traditional methods will be successful at building partnership and consensus among the stakeholders including the local forest dependent communities leading to self tested sustainable approaches to adaptive management (Moller et al. 2004).

\section{Conclusion}

We concludelocal forest users are knowledgeable about their forests including the species, their status and the boundary with the private 
property and other CFs. They possess capacity to take management decisions including trees that can be harvested and distributed. In the meanwhile, the local communities found it difficult to interpret the expert induced GISbased maps. Hence, incorporation of local and scientific knowledge will yield better results and increase the ownership of technical interventions in community forestry.

Despite, forest bureaucracy is devising different mechanisms to govern and control community forest management. The use of sophisticated technologies in small scale participatory community forests is questioned especially in the situation where the users find such illustrations difficult to understand and conflicting with their interest and objectives of forest management.

We argue that use of maps is not neutral form of knowledge rather a continuation of colonial legacy and are tools for exercising power. The use of mapping exercises only using remote sensing and GIS methods in small patches of community forests in Mid-hills of Nepal is used to increase the knowledge holder's superiority rather than actually being useful in forest management planning, management and monitoring. For all of these reasons, we urge the incorporation of local, traditional, and indigenous knowledge in GIS based mapping exercises in community forests such that the user's do not fear the loss of power or suspect domination with excessive use of technology.

\section{Acknowledgments}

Authors acknowledge the support of the local people who participated in the research process, forestry officials and stakeholders who shared their experience with ours. We further acknowledge the financial support received from 'Science and Power in Participatory Forestry' project (13-05KU) funded by the Consultative Research Committee for Development Research under the Danish Ministry of Foreign Affairs. 


\section{References}

Ahlborg, H., \& Nightingale, A. J. (2012). Mismatch between scales of knowledge in Nepalese forestry: epistemology, power, and policy implications. Ecology and Society, 17(4).

Baral, S., Meilby, H., Chettri, B. B. K., Basnyat, B., Rayamajhi, S., \& Awale, S. (2018). Politics of getting the numbers right: Community forest inventory of Nepal. Forest Policy and Economics, 91, 19-26.

Basnyat, B., Treue, T., \& Pokharel, R. K. (2018). Silvicultural madness: a case from the "Scientific Forestry" initiative in the community forests of Nepal. Banko Janakari, 54-64.

Berkes, F., Folke, C., Gadgil, M. (1994). “Traditional Ecological Knowledge." Encyclopedia of Quality of Life and Well-Being Research, 6705-6705.

Carter, J. (1996). Recent approaches to participatory forest resource assessment. Overseas Development Institute (ODI).

Chambers, R. (1994). The origins and practice of participatory rural appraisal. World development, 22(7), 953-969.

GoN/MoFE. 2019. National Forest Policy 2019. Kathmandu, Nepal: Government of Nepal, Ministry of Forests and Environment, Kathmandu, Nepal.

GoN. 2019. "Forest Act, 2019." Government of Nepal.

Goldman, M. (2003). Partitioned nature, privileged knowledge: community-based conservation in Tanzania. Development and change, 34(5), 833-862

Harris, L. M., \& Hazen, H. D. (2005). Power of maps:(Counter) mapping for conservation. ACME: An International Journal for Critical Geographies, 4(1), 99-130.

Hodgson, D. L., \& Schroeder, R. A. (2002). Dilemmas of counter-mapping community resources in Tanzania. Development and change, 33(1), 79-100.

Klopp, J. M., \& Sang, J. K. (2011). Maps, power, and the destruction of the Mau Forest in Kenya. Georgetown Journal of International Affairs, 125-134.

Landis, J. R., \& Koch, G. G. (1977). The measurement of observer agreement for categorical data. biometrics, 159-174.
Lund, J. F. (2015). Paradoxes of participation: The logic of professionalization in participatory forestry. Forest Policy and Economics 60: 1-6.

Mignolo, W. D. (1992). Putting the Americas on the map (geography and the colonization of space). Colonial Latin American Review, 1(12), 25-63.

Moller, H., Berkes, F., Lyver, P. O. B., \& Kislalioglu, M. (2004). Combining science and traditional ecological knowledge: monitoring populations for co-management. Ecology and society, 9(3).

Nightingale, A. J. (2005). “The experts taught us all we know": professionalisation and knowledge in Nepalese community forestry. Antipode, 37(3), 581-604.

Peluso, N. L. (1995). Whose woods are these? Counter-mapping forest territories in Kalimantan, Indonesia. Antipode, 27(4), 383406.

Peluso, N. L. (2005). Seeing property in land use: Local territorializations in West Kalimantan, Indonesia. Geografisk Tidsskrift-Danish Journal of Geography, 105(1), 1-15.

Pokharel, R. K., Rayamajhi, S., \& Tiwari, K. R. (2012). Nepal's community forestry: need of better governance. Global perspectives on sustainable forest management. InTech, Shanghai, China, 43-58.

Poudyal, B. H., Maraseni, T., \& Cockfield, G. (2020). Scientific forest management practice in Nepal: Critical reflections from stakeholders' perspectives. Forests, 11(1), 27.

Raymond, C. M., Fazey, I., Reed, M. S., Stringer, L. C., Robinson, G. M., \& Evely, A. C. (2010). Integrating local and scientific knowledge for environmental management. Journal of environmental management, 91(8), 17661777.

Reid, W., Berkes, F., Wilbanks, T., \& Capistrano, D. (2006). Conclusions: bridging scales and knowledge systems. Bridging Scales and Knowledge Systems: Linking Global Science and Local Knowledge in Assessments, Island Press, Washington, DC, 296-309.

Robbins, P. (2001). Tracking invasive land covers in India, or why our landscapes have never been modern. Annals of the association of American Geographers, 91(4), 637-659.

Robbins, P. (2003). Beyond ground truth: GIS 
and the environmental knowledge of herders, professional foresters, and other traditional communities. Human Ecology, 31(2), 233-253.

Rutt, R. L., Chhetri, B. B. K., Pokharel, R., Rayamajhi, S., Tiwari, K., \& Treue, T. (2015). The scientific framing of forestry decentralization in Nepal. Forest Policy and Economics, 60, 50-61.

Sax, S. (2020). Invisible territory: mapping land-use change and power in the Peruvian Amazon. Journal of Land Use Science, 15(2-3), 290305.

Turner, M. D., \& Hiernaux, P. (2002). The use of herders' accounts to map livestock activities across agropastoral landscapes in Semi-Arid Africa. Landscape Ecology, 17(5), 367-385

Scott, J. C. (1998). Seeing like a state. yale university Press. 